\title{
ChemComm
}

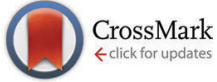

Cite this: Chem. Commun., 2016, 52,5621

Received 11th January 2016 Accepted 17th March 2016

DOI: $10.1039 / \mathrm{c} 6 c c 00264 a$

www.rsc.org/chemcomm

\section{Selective occupancy of methane by cage symmetry in TBAB ionic clathrate hydrate $\uparrow$}

\author{
Sanehiro Muromachi, ${ }^{a}$ Konstantin A. Udachin, ${ }^{b}$ Saman Alavi, ${ }^{b}$ Ryo Ohmura ${ }^{c}$ and \\ John A. Ripmeester ${ }^{\text {b }}$
}

\begin{abstract}
Methane trapped in the two distinct dodecahedral cages of the ionic clathrate hydrate of TBAB was studied by single crystal XRD and MD simulation. The relative $\mathrm{CH}_{4}$ occupancies over the cage types were opposite to those of $\mathrm{CO}_{2}$, which illustrates the interplay between the cage symmetry and guest shape and dynamics, and thus the gas selectivity.
\end{abstract}

Methane is the smallest hydrocarbon molecule which interacts with water hydrophobically. For the class of clathrate hydrates including the ionic or salt hydrates, methane is a suitable guest substance that fits well into the pentagonal dodecahedral (D) cages made of hydrogen-bonded water molecules. ${ }^{1}$ The molecular size and the quasi-spherical shape of methane promote an isotropic distribution which is compatible with the void space of the D cages which can have a variety of local symmetries. Some recently obtained understanding of guest distributions in ionic clathrate hydrates suggests a novel method for modifying the preference of guest occupancies by controlling the $\mathrm{D}$ cage symmetries. ${ }^{2}$

The ionic clathrate hydrates form from water and ionic guests such as tetra- $n$-butylammonium bromide (TBAB) $)^{3}$ under relatively mild conditions, e.g., $290 \mathrm{~K}$ for $\mathrm{CH}_{4}+\mathrm{TBAB}$ hydrates versus $275 \mathrm{~K}$ for the cubic sI $\mathrm{CH}_{4}$ hydrate, at $3 \mathrm{MPa}^{4}{ }^{4}$ Hence many potential applications of these materials are suggested, e.g., gas separation and cool energy storage. ${ }^{5}$ Ionic hydrates can have the $\mathrm{D}$ cages occupied by small secondary guest gases, e.g., $\mathrm{CH}_{4}, \mathrm{~N}_{2}$ and $\mathrm{CO}_{2}^{2,4 c, 6}$ In the hydrate structures formed with tetra- $n$-butylammonium and tetra- $n$-butylphosphonium salts,

\footnotetext{
${ }^{a}$ Research Institute of Energy Frontier, National Institute of Advanced Industrial Science and Technology (AIST), 16-1 Onogawa, Tsukuba, 305-8569, Japan. E-mail: s-muromachi@aist.go.jp

${ }^{b}$ National Research Council of Canada, 100 Sussex Drive, Ottawa, ON, K1A OR6, Canada

${ }^{c}$ Department of Mechanical Engineering, Keio University, Yokohama 223-8522, Japan

$\dagger$ Electronic supplementary information (ESI) available: Experimental and computational details. CCDC 1431843. For ESI and crystallographic data in CIF or other electronic format see DOI: 10.1039/c6cc00264a
}

there are two distinct types of D cages with significantly different shapes, particularly due to the water displacement by the large cation. ${ }^{7}$ Although they have almost the same volume, the distorted D cage $\left(D_{A}\right)$ and relatively regular $D$ cage $\left(D_{B}\right)$ have very different cage occupancies by $\mathrm{CO}_{2}$, i.e., 0.867 versus 0.490 , respectively, with each cage having the anisotropic angular distribution for $\mathrm{CO}_{2}{ }^{2}$ So far, the $\mathrm{D}_{\mathrm{A}}$ cage found in the TBAB hydrates has shown that it would provide different selectivity even for similarly sized molecules such as $\mathrm{N}_{2}$ and $\mathrm{CO}_{2}{ }^{1 b, 6 b}$ Here, we consider $\mathrm{CH}_{4}$, which is a preferred guest molecule for the spherical D cage in most of the known hydrate structures, as a guest gas in the TBAB hydrate cages.

We determined the structure of the $\mathrm{TBAB}+\mathrm{CH}_{4}$ hydrate by single crystal X-ray diffraction (SCXRD) measurements. The crystallographic details are given in Notes $\ddagger$ and the ESI. $\dagger$ It has an Pmma orthorhombic lattice with a $21.0329(15) \times 12.5972(9) \times 12.0333(8) \AA^{3}$ cell size in agreement with Jeffrey's type IV hydrate structure as well as the TBAB $+\mathrm{CO}_{2}$ hydrate. ${ }^{2,3 a}$ The cell size is slightly shrunk from the pure ТВAB hydrate $\left(21.060(5) \times 12.643(4) \times 12.018(8) \AA^{3}\right.$ at $93.1 \mathrm{~K})^{7 a}$ likely due to the $\mathrm{CH}_{4}$ occupancy and attractive $\mathrm{CH}_{4}$-water interactions, however, the unit cell is not doubled along the $b$-axis in contrast to the Imma lattice of the TBAB $+\mathrm{CO}_{2}$ hydrate with unit cell vectors of 21.0197(7), 25.2728(8), and 12.0096(4) $\AA^{2}{ }^{2}$ If we assume that the Imma structure has the $b$-lattice length simply double that of the Pmma structure, actually this is not true as shown later, the ratios of the axes based on the present Pmma structure of the TBAB $+\mathrm{CH}_{4}$ hydrate are 1.00, 2.01 and 1.00 for $a, b$ and $c$ axes, respectively. These values show that the unit cell size of the Imma structure is scarcely affected by $\mathrm{CO}_{2}$, and the symmetry lowering is due to the aforementioned local interactions in the $\mathrm{D}$ cages between the host water and the $\mathrm{CO}_{2}$ guests. The chemical composition of the crystal unit cell was determined to be TBAB $38 \mathrm{H}_{2} \mathrm{O} \cdot 2 \cdot 16 \mathrm{CH}_{4}$. Methods and results of SCXRD measurements have been detailed in our previous papers ${ }^{2,7 b, c}$ and the ESI. $\dagger$ As in the case of TBAB $+\mathrm{CO}_{2}$ hydrate, the TBA cation was incorporated into a fused $\mathrm{T}^{2} \mathrm{P}^{2}$ supercage, built out of two tetrakaidecahedral (T) cages having 12 pentagonal faces and two hexagonal faces, and two pentakaidecahedral (P) cages having 12 pentagonal faces and three hexagonal faces (see Fig. S1 in the ESI†). 


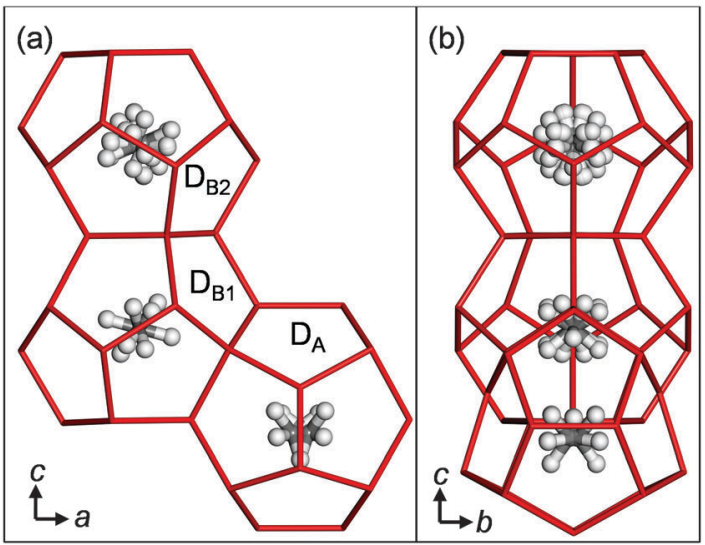

Fig. 1 Three $D$ cages in the TBAB $+\mathrm{CH}_{4}$ hydrate. (a) A view from the $b$ axis. (b) A view from the a axis.

The bromide anion replaces a water molecule in the lattice of the $\mathrm{T}^{2} \mathrm{P}^{2}$ cage and some water molecules are missing at the vertices where the cages join in order to accommodate the large cations. The cation and anion positions were the same as for the $\mathrm{TBAB}+\mathrm{CO}_{2}$ hydrate and the simple TBAB hydrate in the absence of guest gas. ${ }^{2,7 a}$ Three distinct $\mathrm{D}$ cages were found in the structure as shown in Fig. 1: a strongly distorted cage $\left(\mathrm{D}_{\mathrm{A}}\right)$ and two relatively regular cages $\left(D_{B 1}\right.$ and $\left.D_{B 2}\right)$, thus the cage framework can be described as $\mathrm{T}^{2} \mathrm{P}^{2} \cdot \mathrm{D}_{\mathrm{A}} \cdot \mathrm{D}_{\mathrm{B} 1} \cdot \mathrm{D}_{\mathrm{B} 2}$. Symmetries of both $\mathrm{D}_{\mathrm{B} 1}$ and $\mathrm{D}_{\mathrm{B} 2}$ cages were $2 / m$, therefore, these should be identical for $\mathrm{CH}_{4}$. Cage occupancies by $\mathrm{CH}_{4}$ were 0.174 for $\mathrm{D}_{\mathrm{A}}, 0.989$ for $\mathrm{D}_{\mathrm{B} 1}$ and 0.993 for $\mathrm{D}_{\mathrm{B} 2}$. Table 1 compares the $\mathrm{D}$ cages in the $\mathrm{TBAB}+\mathrm{CH}_{4}$ and $\mathrm{TBAB}+\mathrm{CO}_{2}$ hydrates. The relative $\mathrm{CH}_{4}$ occupancies of the $\mathrm{D}_{\mathrm{A}}$ and $\mathrm{D}_{\mathrm{B}}$ cages were opposite to those of $\mathrm{CO}_{2}{ }^{2}$.

The results show that $\mathrm{CH}_{4}$ molecules prefer the regular quasi-spherical $D_{B}$ cages rather than the distorted aspherical $D_{A}$ cage, whereas $\mathrm{CO}_{2}$ prefers the elongated $\mathrm{D}_{\mathrm{A}}$ cage. The averaged occupancies over all cage types by $\mathrm{CH}_{4}$ and $\mathrm{CO}_{2}$ are close to each other, i.e., 0.719 and 0.616, respectively. Table S2 in the ESI $\uparrow$ further compares the D cage symmetries between ionic and canonical clathrate hydrates. This relationship between $\mathrm{D}$ cage occupancies gives an explanation for the formation conditions of TBAB hydrate formed with $\mathrm{CH}_{4}$ and/or $\mathrm{CO}_{2}{ }^{4 c, 6 a, 8}$ (see Fig. 2). Phase equilibrium data of the TBAB $+\mathrm{CH}_{4}$ and TBAB $+\mathrm{CO}_{2}$ hydrates with TBAB mole fractions in the aqueous phase $x_{\mathrm{TBAB}}=0.013$ and 0.026 are available. $^{4 c, 6 a}$ They are fairly close as shown in Fig. 2. With $x_{\mathrm{TBAB}} \sim 0.013$, equilibrium conditions of TBAB hydrates formed with $\mathrm{CH}_{4}+\mathrm{CO}_{2}$ mixed gas were also reported. ${ }^{8}$ With this solution, there is about $0.3 \mathrm{~K}$ of equilibrium temperature difference between $\mathrm{TBAB}+\mathrm{CH}_{4}$ and $\mathrm{TBAB}+\mathrm{CO}_{2}$ hydrates. However, $\mathrm{TBAB}+\mathrm{CH}_{4}+\mathrm{CO}_{2}$

Table 1 The D cage symmetries and occupancies in the TBAB hydrate structure

\begin{tabular}{llllll}
\hline & $\mathrm{D}_{\mathrm{A}}$ cage & & & $\mathrm{D}_{\mathrm{B}}$ cage & \\
\cline { 2 - 3 } Gas & Symmetry & Occupancy & & Symmetry & Occupancy \\
\hline $\mathrm{CH}_{4}{ }_{\mathrm{C}}{ }^{b}$ & $m m 2$ & 0.174 & $2 / m$ & $0.991^{a}$ \\
$\mathrm{CO}_{2}$ & $2 / m$ & 0.867 & & 2 & 0.490
\end{tabular}

${ }^{a}$ An averaged value for $\mathrm{D}_{\mathrm{B} 1}$ and $\mathrm{D}_{\mathrm{B} 2}$ cages. ${ }^{b}$ Reported in ref. 2.

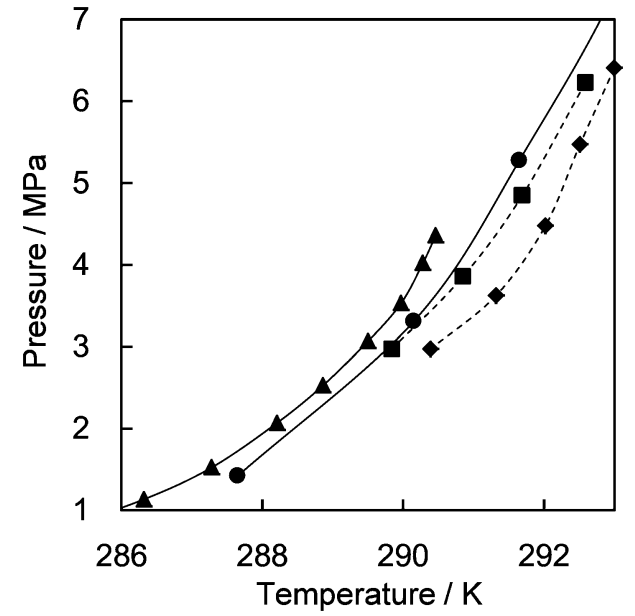

Fig. 2 Phase diagram for TBAB $+\mathrm{CH}_{4}$ and/or $\mathrm{CO}_{2}$ hydrates. $\mathrm{TBAB}+\mathrm{CO}_{2}$ hydrate: ${ }^{6 a} \triangle, x_{\mathrm{TBAB}}=0.026 ; \boldsymbol{\Lambda}_{,} x_{\mathrm{TBAB}}=0.013 . \mathrm{TBAB}+\mathrm{CH}_{4}$ hydrates: ${ }^{4 c} \mathrm{O}$, $x_{\mathrm{TBAB}}=0.023 ; \bullet, x_{\mathrm{TBAB}}=0.014 . \mathrm{TBAB}+\mathrm{CH}_{4}+\mathrm{CO}_{2}: 8, x_{\mathrm{TBAB}}=0.014$, $y_{\mathrm{CO}_{2}}=\sim 0.55 ; \mathbf{\square}, x_{\mathrm{TBAB}}=0.014, y_{\mathrm{CO}_{2}}=\sim 0.35$, where $x_{\mathrm{TBAB}}$ and $y_{\mathrm{CO}_{2}}$ denote the mole fraction of TBAB in an aqueous phase and the mole fraction of $\mathrm{CO}_{2}$ in a gas phase, respectively.

hydrates show higher equilibrium temperatures, $\sim 1 \mathrm{~K}$ higher than the TBAB $+\mathrm{CH}_{4}$ or $\mathrm{CO}_{2}$ hydrate. In addition, the mixed $\mathrm{CH}_{4}+\mathrm{CO}_{2}$ gas hydrate in the incongruent solution $\left(x_{\mathrm{TBAB}}=\right.$ $0.014)$ is as stable as the $\mathrm{TBAB}+\mathrm{CO}_{2}$ and $\mathrm{TBAB}+\mathrm{CH}_{4}$ hydrates in the congruent solution $\left(x_{\mathrm{TBAB}}=0.026\right.$ with the hydration number: 38). This is likely due to the fact that the distorted $\mathrm{D}_{\mathrm{A}}$ cages are occupied by $\mathrm{CO}_{2}$ and the regular $\mathrm{D}_{\mathrm{B}}$ cages are occupied by $\mathrm{CH}_{4}$. Consequently, the TBAB hydrate structure may be stabilized with the mixed gas.

Fig. 3 shows the cages with different shapes and symmetries occupied by $\mathrm{CH}_{4}$ and $\mathrm{CO}_{2}$. In the $\mathrm{D}_{\mathrm{A}}$ cage, $\mathrm{CH}_{4}$ is displaced from the central position along the $c$ axis. In contrast, the carbon atom of $\mathrm{CO}_{2}$ is located at the center, and the $\mathrm{CO}_{2}$ guests have rotational motion in a plane which is almost perpendicular to the $b$ axis and along the $c$ axis.

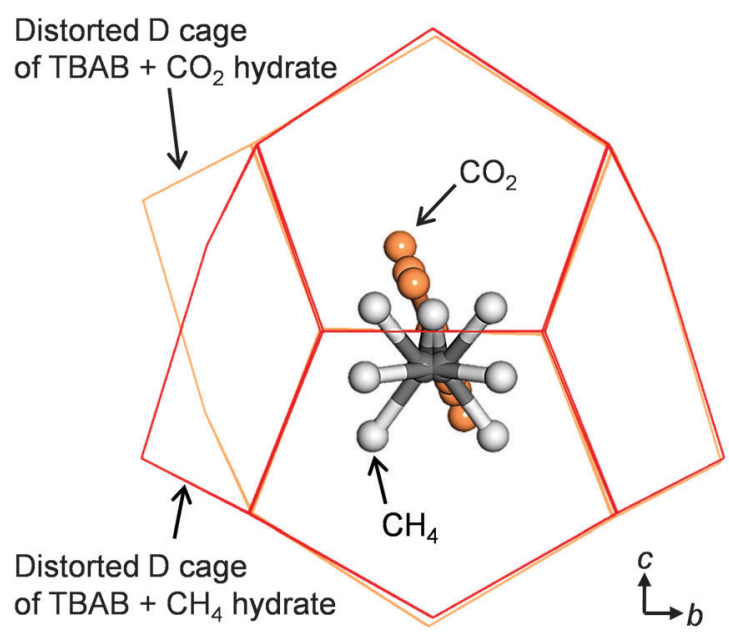

Fig. 3 Comparison of guest gas positions between $\mathrm{CH}_{4}$ and $\mathrm{CO}_{2}^{2}$ in the distorted $D$ cage $\left(D_{A}\right)$ of TBAB hydrate from a view of the a-axis. 
We performed molecular dynamics (MD) simulations on this system with $\mathrm{CH}_{4}$ cage occupancies corresponding to experimental values. The goal of the simulations is to detect the differences of structural and dynamical aspects of the methane guest motions in the two types of D cages. The details of the MD simulations are given in Notes $\neq$ and the ESI. $\dagger$ In Fig. 4 we show the calculated radial distribution function (RDF) for cage water oxygen atoms with the methane carbon atoms at 150 and $250 \mathrm{~K}$.

The $\mathrm{D}_{\mathrm{A}}$ cages are distorted and elongated along the direction which allows the methane guest molecules to approach some cage water molecules at distances between 3 and $3.2 \AA$ A. There is much smaller probability of seeing methane molecules in the $D_{B}$ cages within this distance range of the cage waters. The elongation of the $D_{A}$ cage also leads to the first peak in the C. . OW RDF in the $\mathrm{D}_{\mathrm{A}}$ cage being broader than the peaks in the $\mathrm{D}_{\mathrm{B}}$ cages. As the ionic clathrate hydrate does not dissociate over the temperature range of the simulations ( $150 \mathrm{~K}$ to $250 \mathrm{~K}$ ), there will not be a change in the coordination number of the methane guests in the $D_{A}$ and $D_{B}$ cages, with respect to water oxygens, associated with the changes in temperature. The changes in the RDF include broadening of the first peaks at higher temperature which is related to the increase of amplitude of the methane motions in the cages.

The dynamics of the methane molecules in the $\mathrm{D}$ cages is studied using the velocity autocorrelation function (VACF), $\psi(t)=\left\langle\nu_{i}(t) \cdot \nu_{i}(0)\right\rangle /\left\langle\nu_{i}(0) \cdot \nu_{i}(0)\right\rangle$ where $\nu_{\mathrm{i}}(t)$ is the velocity of methane $i$ at time $t$ and the brackets represent an average over all methane molecules in a particular type of $\mathrm{D}$ cage. The velocity autocorrelation functions for methane in the $\mathrm{D}_{\mathrm{A}}, \mathrm{D}_{\mathrm{B} 1}$, and $\mathrm{D}_{\mathrm{B} 2}$ cages at 150 and $250 \mathrm{~K}$ are shown in Fig. 5.

The motions of the methane molecules in the $\mathrm{D}_{\mathrm{B} 1}$ and $\mathrm{D}_{\mathrm{B} 2}$ cages are more regular and a greater number of rattling vibration cycles are observed in these cage types before the motion is randomized. The motions of the methane molecules in the $\mathrm{D}_{\mathrm{A}}$ cages have a smaller initial period and the VACF of the methane guests in

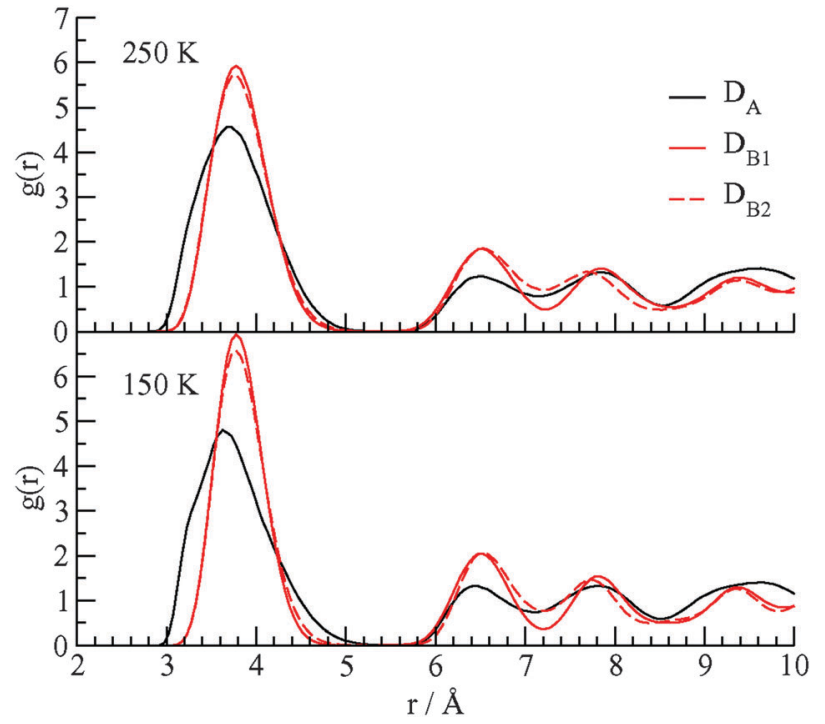

Fig. 4 The RDF for the methane carbon atom-water oxygen atom in the three $\mathrm{D}$ cages of the $\mathrm{TBAB}+\mathrm{CH}_{4}$ ionic hydrate at 150 and $250 \mathrm{~K}$.

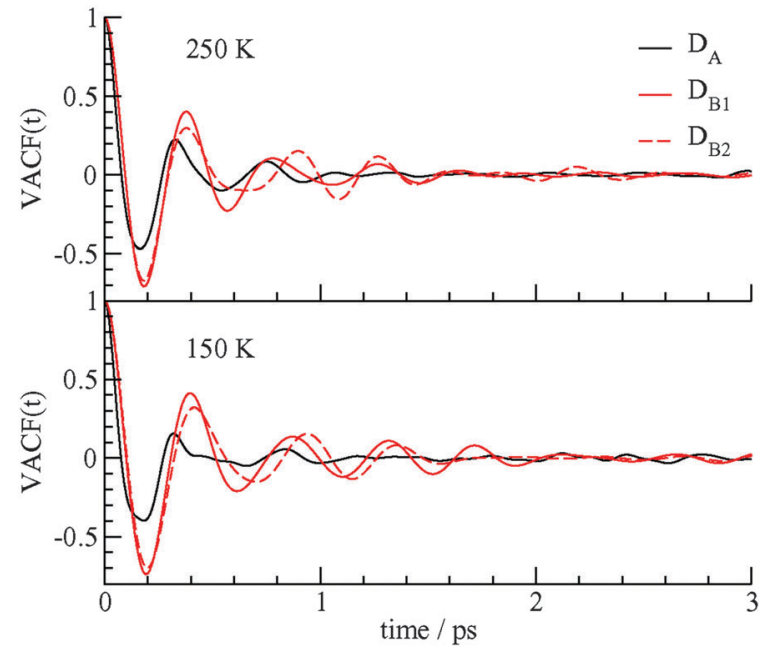

Fig. 5 The velocity autocorrelation function of the methane carbon atoms in the $D_{A}, D_{B 1}$, and $D_{B 2}$ cages at 150 and $250 \mathrm{~K}$.

the $\mathrm{D}_{\mathrm{A}}$ cages decays to 0 after about $1 \mathrm{ps}$, whereas periodic behavior for the motion of the methane guests in the $\mathrm{D}_{\mathrm{B}}$ cages continues over times of 2 ps or longer. The dynamics of the methane molecules in the $\mathrm{D}_{\mathrm{B} 1}$ and $\mathrm{D}_{\mathrm{B} 2}$ cages are somewhat different and $\psi(t)$ is sensitive enough to differentiate between these two cage types. The different dynamics of the methane guests in the $\mathrm{D}_{\mathrm{A}}$ and $\mathrm{D}_{\mathrm{B}}$ cages may lead to different spectroscopic signatures for the guests in the two types of cages. The VACF at different temperatures also reflect the higher amplitude, slightly higher frequency motion, and faster decay of velocity correlations of methane guests at $250 \mathrm{~K}$ compared to $150 \mathrm{~K}$. These results of Fig. 4 and 5 confirm that the low symmetry D cages hold the methane guest molecules more loosely than the more structurally regular $\mathrm{D}_{\mathrm{B}}$ cages.

The results of methane uptake by TBAB show that physical adsorption properties of clathrate hydrates for developing gas capture technology can be further improved by crystal engineering with ionic guests. For example, to maximize the separation of $\mathrm{CO}_{2}$ from methane it would be best to have a clathrate host that would have all asymmetric cages to select $\mathrm{CO}_{2}$ over methane. So far, the drastic differences in $\mathrm{D}$ cage capacities for $\mathrm{CH}_{4}$ and $\mathrm{CO}_{2}$ have remained unknown and all $\mathrm{D}$ cages have been treated as identical. Information as obtained in these structural studies is also critically important for developing quantitative models for the sorption behavior.

This study was subsidized in part by the Keio University Global Center of Excellence Program. SM thanks for the support provided by the Japan Society for the Promotion of Science (JSPS) (grant no. 23-56572).

\section{Notes and references}

$\ddagger$ Crystallographic data for TBAB $38 \mathrm{H}_{2} \mathrm{O} \cdot 0.688 \mathrm{CH}_{4}$ : $\mathrm{MoK} \alpha$ radiation $(\lambda=0.71070 \AA)$, crystal size $0.6 \times 0.2 \times 0.2 \mathrm{~mm}$, orthorhombic, space group Pmma, $a=21.0329(15) \AA, b=12.5972(9) \AA, c=12.0333(8) \AA, Z=2$, volume 3188.3(4) $\AA^{3}$, density $1.067 \mathrm{~g} \mathrm{~cm}^{-3} ; \mu(\mathrm{MoK} \alpha)=0.723 \mathrm{~mm}^{-1}$, temperature $100.0(1) \mathrm{K}$, scan mode $(1.69<2 \theta<29.00)$, reflections collected/unique 4515/4169, 528 parameters. The structure was solved 
and refined using the SHELX program ${ }^{9}$ with full matrix least squares on $F^{2}$, GOF $\left(F^{2}\right) 1.175$; final $R$ indices $(I>2 \sigma(I)): R_{1}=0.0549, \mathrm{w} R_{2}=0.1649$; $R$ indices (all data) $R_{1}=0.0592, \mathrm{w} R_{2}=0.1670$. CCDC 1431843. The intermolecular van der Waals potentials between atoms in different molecules are considered to be the sum of Lennard-Jones (LJ) and electrostatic point charges. The TIP4P four-charge water molecular model was used. ${ }^{10}$ TBA ions were modelled with the general AMBER force field, ${ }^{11}$ and the force field for bromide by Canongia Lopes and Pádua. ${ }^{12}$ The Tse-Klein-McDonald potential ${ }^{1 h}$ was chosen for methane helper guest molecules. Partial electrostatic charges on the atoms of the guest molecules were determined from charges using electrostatic potential grid (CHELPG) calculations ${ }^{13}$ with the Gaussian 09 suite of programs ${ }^{14}$ at the B3LYP/6-311++G(d,p) level of theory. Temperatures of 100 (X-ray structure determination temperature), 200, and $250 \mathrm{~K}$ with ambient pressure were used in the simulations. The used parameters and further detailed methods are given in the ESI.†

1 (a) D. W. Davidson and J. A. Ripmeester, in Inclusion Compounds, ed. J. L. Atwood, J. E. D. Davies and D. D. MacNicol, Academic Press, London, 1984, ch. 3, vol. 3; (b) J. A. Ripmeester and C. I. Ratcliffe, Energy Fuels, 1998, 12, 197-200; (c) J. A. Ripmeester, J. S. Tse, C. I. Ratcliffe and B. M. Powell, Nature, 1987, 325, 135-136; (d) S. Subramanian and E. D. Sloan, Fluid Phase Equilib., 1999, 158-160, 813-820; (e) T. Uchida, R. Okabe, K. Gohara, S. Mae, Y. Seo, H. Lee, S. Takeya, J. Nagao, T. Ebinuma and H. Narita, Can. J. Phys., 2003, 81, 359-366; (f) R. Susilo, J. A. Ripmeester and P. Englezos, Chem. Eng. Sci., 2007, 62, 3930-3939; (g) P. M. Rodger, J. Phys. Chem., 1990, 94, 6080-6089; (h) J. S. Tse, M. L. Klein and I. R. McDonald, J. Phys. Chem., 1983, 87, 4198-4203; (i) H. Tanaka and K. Kiyohara, J. Chem. Phys., 1993, 98, 8110-8118; $(j)$ M. Hiratsuka, R. Ohmura, A. K. Sum and K. Yasuoka, J. Chem. Phys., 2012, 137, 044508.

2 S. Muromachi, K. A. Udachin, K. Shin, S. Alavi, I. L. Moudrakovski, R. Ohmura and J. A. Ripmeester, Chem. Commun., 2014, 50, 11476-11479.

3 (a) G. A. Jeffrey, in Inclusion Compounds, ed. J. L. Atwood, J. E. D. Davies and D. D. MacNicol, Academic Press, London, 1984, ch. 5, vol. 1; (b) Y. A. Dyadin and K. A. Udachin, J. Struct. Chem., 1987, 28, 75-116.

4 (a) S. Adisasmito, R. J. Frank III and E. D. Sloan Jr., J. Chem. Eng. Data, 1991, 36, 68-71; (b) K. Yasuda and R. Ohmura, J. Chem. Eng. Data, 2008, 53, 2182-2188; (c) M. Arjmandi, A. Chapoy and B. Tohidi, J. Chem. Eng. Data, 2007, 52, 2153-2158.

5 (a) P. Zhang, Z. W. Ma and R. Z. Wang, Renewable Sustainable Energy Rev., 2010, 14, 598-614; (b) A. Chapoy, R. Anderson and B. Tohidi, J. Am. Chem. Soc., 2007, 129, 746-747; (c) N. H. Duc, F. Chauvy and J.-M. Herri, Energy Convers. Manage., 2007, 48, 1313-1322.

6 (a) N. Ye and P. Zhang, J. Chem. Eng. Data, 2012, 57, 1557-1562; (b) S. Muromachi, H. Hashimoto, T. Maekawa, S. Takeya and Y. Yamamoto, Fluid Phase Equilib., 2016, 413, 249-253.

7 (a) W. Shimada, M. Shiro, H. Kondo, S. Takeya, H. Oyama, T. Ebinuma and H. Narita, Acta Crystallogr., Sect. C: Cryst. Struct. Commun., 2005, C61, o65-o66; (b) S. Muromachi, S. Takeya, Y. Yamamoto and R. Ohmura, CrystEngComm, 2014, 16, 2056-2060; (c) T. Kobori, S. Muromachi, T. Yamasaki, S. Takeya, Y. Yamamoto, S. Alavi and R. Ohmura, Cryst. Growth Des., 2015, 15(8), 3862-3867.

8 H. Y. Acosta, P. R. Bishnoi and M. A. Clarke, J. Chem. Eng. Data, 2011, 56, 69-73.

9 (a) G. M. Sheldrick, Acta Crystallogr., 1990, A46, 467; (b) G. M. Sheldrick, Acta Crystallogr., 1993, A49(suppl), C53.

10 J. L. F. Abascal, E. Sanz, R. Garcia Fernandez and C. Vega, J. Chem. Phys., 2005, 122, 234511.

11 W. D. Cornell, P. Cieplak, C. L. Bayly, I. R. Gould, K. M. Merz Jr., D. M. Ferguson, D. C. Spellmeyer, T. Fox, J. W. Caldwell and P. A. Kollman, J. Am. Chem. Soc., 1995, 117, 5179See also, http://ambermd. org.

12 J. N. Canongia Lopes and A. A. H. Pádua, J. Phys. Chem., 2006, 110, 19586-19595.

13 C. M. Breneman and K. B. Wiberg, J. Comput. Chem., 1990, 11, 361. 14 M. J. Frisch, G. W. Trucks, H. B. Schlegel, G. E. Scuseria, M. A. Robb, J. R. Cheeseman, G. Scalmani, V. Barone, B. Mennucci and G. A. Petersson, et al., Gaussian 09, Revision D.01, Gaussian, Inc., Wallingford CT, 2009. 